\title{
No correlation between femoral tunnel orientation and clinical outcome at long-term follow-up after non-anatomic anterior cruciate ligament reconstruction
}

\author{
David Sundemo $^{1}(\mathbb{0})$ Julia Mårtensson ${ }^{1} \cdot$ Eric Hamrin Senorski $^{1}$. Eleonor Svantesson ${ }^{1} \cdot$ Jüri Kartus $^{2} \cdot$ Ninni Sernert $^{2}$. \\ Jón Karlsson ${ }^{1,3} \cdot$ Kristian Samuelsson $^{1,3}$
}

Received: 28 September 2018 / Accepted: 18 January 2019 / Published online: 1 February 2019

(c) The Author(s) 2019

\begin{abstract}
Purpose This study aimed to determine the influence of femoral tunnel orientation on long-term clinical outcome and osteoarthritis in patients undergoing ACL reconstruction and to test the reliability of the implemented radiographic measurement methods. It was hypothesized that a more horizontal femoral tunnel would correlate with superior clinical outcome.

Methods A cohort of 193 patients who underwent non-anatomic ACL reconstruction was examined. In this specific study, non-anatomic is defined by the surgeons' pursuit of optimal isometry, not to emulate the native ACL anatomy. At follow-up, the Lachman test, the KT-1000, the pivot-shift test, the one-leg-hop test and the IKDC-2000 were evaluated. Osteoarthritis was evaluated radiographically. Posteroanterior and lateral radiographs were used to determine the position of the femoral tunnel in the coronal and sagittal planes and the angle of the tunnel in the coronal plane. A method for determining femoral rotation on the lateral radiographs was developed and its reliability was evaluated. The femoral tunnel orientation was analyzed to examine its influence on clinical outcome and osteoarthritis.

Results A total of 101 patients were analyzed at a mean of $16.4( \pm 1.3)$ years postoperatively. The reliability of the measurement methods was regarded as good to excellent (ICC 0.57-0.97). The mean coronal femoral tunnel angle was $9.6^{\circ}\left( \pm 9.4^{\circ}\right)$. The coronal femoral tunnel was positioned at a mean of $43 \%( \pm 3.5 \%)$ of the distance measured from lateral to medial. The mean sagittal femoral tunnel position, measured using the quadrant method, was $40 \%$ ( $\pm 6.4 \%$ ) from posterior to anterior. No significant associations were found between tunnel orientation and the clinical outcome variables.

Conclusions The orientation of the femoral tunnel did not predict the long-term subjective outcome, functional outcome or the development of osteoarthritis in patients undergoing non-anatomic ACL reconstruction. The method for determining femoral rotation on lateral radiographs was found to be reliable.
\end{abstract}

Level of evidence Retrospective cohort study, level of evidence IV.

Keywords Anterior cruciate ligament reconstruction · Osteoarthritis $\cdot$ Radiographs $\cdot$ Surgery $\cdot$ Outcome $\cdot$ Femoral tunnel angle $\cdot$ Quadrant method

David Sundemo

David.sundemo@outlook.com

1 Department of Orthopaedics, Institute of Clinical Sciences, The Sahlgrenska Academy, University of Gothenburg, Gothenburg, Sweden

2 NU-Hospital Group, Trollhättan/Uddevalla, Sweden

3 Department of Orthopaedics, Sahlgrenska University Hospital, Mölndal, Sweden

\section{Introduction}

The position and angle of the bone tunnels in anterior cruciate ligament (ACL) reconstruction are central aspects, which can affect laxity restoration, loss of motion and the future risk of developing osteoarthritis (OA) [11, 26]. Incorrect tunnel placement has been shown to be a common cause of technical failure in ACL reconstruction [23, 25, 32, 33].

During the past decade, there has been a shift from isometric, non-anatomic $\mathrm{ACL}$ reconstruction, often performed using the transtibial (TT) technique, to a more anatomic approach, which could be performed using transportal (TP) techniques 
[9]. The graft in anatomic ACL reconstruction is oblique and horizontal, in both the coronal and sagittal planes [14]. As a result, it has been suggested that anatomic ACL reconstruction improves the rotational laxity of the knee and consequently decreases the pivot-shift phenomenon [1, 20]. In anatomic ACL reconstruction, the femoral tunnel is placed using either a single- or double-bundle technique, aiming at the native femoral footprint with the aid of intra-articular anatomic landmarks [1]. As a result, the differences between non-anatomic and anatomic ACL reconstruction are predominantly the position and angle of the bone tunnels. To investigate the influence of tunnel orientation, several previous studies have examined postoperative tunnel placement radiographically with regard to clinical outcome [11, 26, 29]. A more horizontal femoral tunnel in the coronal plane has been associated with superior results in terms of rotatory knee laxity, the development of OA and subjective outcome [16, 26]. However, to the authors' knowledge, no study to date, with more than 10 years of follow-up, has assessed the long-term influence of femoral tunnel orientation on the clinical outcome.

A review of the literature reveals that various methods for the postoperative radiographic assessment after ACL reconstruction have been developed and utilized, but only a few have been tested with regard to reliability $[2,12,14,26]$. The reliability of radiographic techniques in determining tunnel orientation varies between studies, making it important to validate measurement reliability in this field. One issue complicating the assessment of radiographs is to determine the amount of rotation of the distal femur seen on standard lateral radiographs. A sufficient overlap of the femoral condyles is desirable to ensure a lateral projection. Arbitrary methods have frequently been used to determine whether an adequate projection has been obtained. The use of fluoroscopy, where true lateral projections can be assured, is a good alternative, although this technique is not always available.

The purpose of this study was to determine the influence of femoral tunnel orientation on long-term clinical outcome and osteoarthritis in patients undergoing ACL reconstruction and to test the reliability of the implemented radiographic measurement methods. Moreover, the purpose was to test the reliability of a new method that was created to standardize the analysis of femoral rotation on lateral radiographs. The hypothesis of the study was that patients with more horizontal femoral tunnels, in both the coronal and sagittal projections, would experience a superior clinical outcome and less $\mathrm{OA}$ in the long term.

\section{Materials and methods}

In this retrospective analysis of two previously published randomized, controlled trials [7, 19], a total of 193 patients were recruited from three medical centers in Sweden.
Patients with an ACL rupture and only minor chondral lesions (Outerbridge grades 1 to 2) were included. Meniscal injuries were not considered a reason for exclusion. Patients suffering from major chondral lesions, multiligament injuries or a previous ACL reconstruction of the ipsilateral or contralateral knee were excluded from the study. ACL reconstructions were performed by one of six experienced senior surgeons and patients were divided into three groups receiving an ipsilateral patellar tendon autograft, an ipsilateral three-strand semitendinosus autograft or an ipsilateral four-strand semitendinosus/gracilis autograft. Reconstructions were performed from September 1995 through January 2000. The surgical technique and postoperative rehabilitation protocol have been described in detail in a previous study [4]. The term "non-anatomic ACL reconstruction" is used to explain that the surgeons did not pursue native ACL anatomy but instead aimed to create graft isometry, which was a common method at the time the study was initiated. The study was approved by the Human Ethics Committee at Gothenburg University and Stockholm University. Written informed consent was obtained from all patients.

\section{Clinical assessments and follow-up}

Preoperative and postoperative assessments were performed by a research assistant or physical therapists who were not involved in the surgery or rehabilitation. Anteroposterior knee laxity was measured using the Lachman test (graded as $0,1+, 2+$ or $3+)$ and using a KT-1000 arthrometer [6] (MEDmetric San Diego, CA) to perform the manual maximum test. To assess rotatory knee laxity, the standardized pivot-shift test [10], developed from the original technique presented by Galway and MacIntosh, was used [8]. The pivot-shift test was graded according to IKDC criteria as normal, glide, clunk and gross (or $0,1+, 2+, 3+$ ). Both the Lachman test and the pivot-shift test were dichotomized for the purpose of analysis. Dichotomization was performed to differentiate between patients with totally stable knees and patients with instability, independent of the degree of instability. Consequently, the two subgroups contain patients with grade 0 vs. patients with grade $1+, 2+$ and $3+$. To evaluate knee function, the one-leg-hop test [31] was used and compared with the contralateral side using a quotient. Subjective outcome was assessed using the IKDC 2000 subjective knee evaluation form [15].

\section{Radiologic assessment}

At the long-term follow-up, bilateral weight-bearing radiographs with the knee in $30-45^{\circ}$ of flexion were obtained in the posteroanterior, lateral and patellofemoral projections. To grade osteoarthritis of the knees, the Kellgren-Lawrence classification was used [17]. Grading was performed by one 
senior radiologist with extensive experience of orthopedic radiographic evaluations. For the purpose of analysis, patients were dichotomized into subgroups with either none to mild $(0-1)$ or moderate to severe (2-4) radiographic signs of osteoarthritis. To validate interrater reliability, the positions and angles of the tunnels were reviewed independently by two of the authors. Further, 2 weeks after the first review, the measurements were repeated to determine intraobserver reliability. Measurements were made using Centricity Enterprise Web V4.0 (General Electric Healthcare, Barrington, Illinois, USA), a software program that enables the determination of angles and distances. In the final analysis, only measurements from the first review by one examiner were used.

The position of the femoral tunnel in the coronal plane was measured on the posteroanterior radiograph. The largest distance between the medial and lateral femoral condyles was identified (A). The distance from the lateral condyle to the center of the tunnel was measured (a). The obtained distance (a) was divided by the total width (A) and the position of the femoral tunnel was expressed as a percentage (Fig. 1).

To evaluate the angle of the femoral tunnel in the coronal plane, a method recently published by Illingworth et al. [14] was implemented. The most proximal portion of the femoral

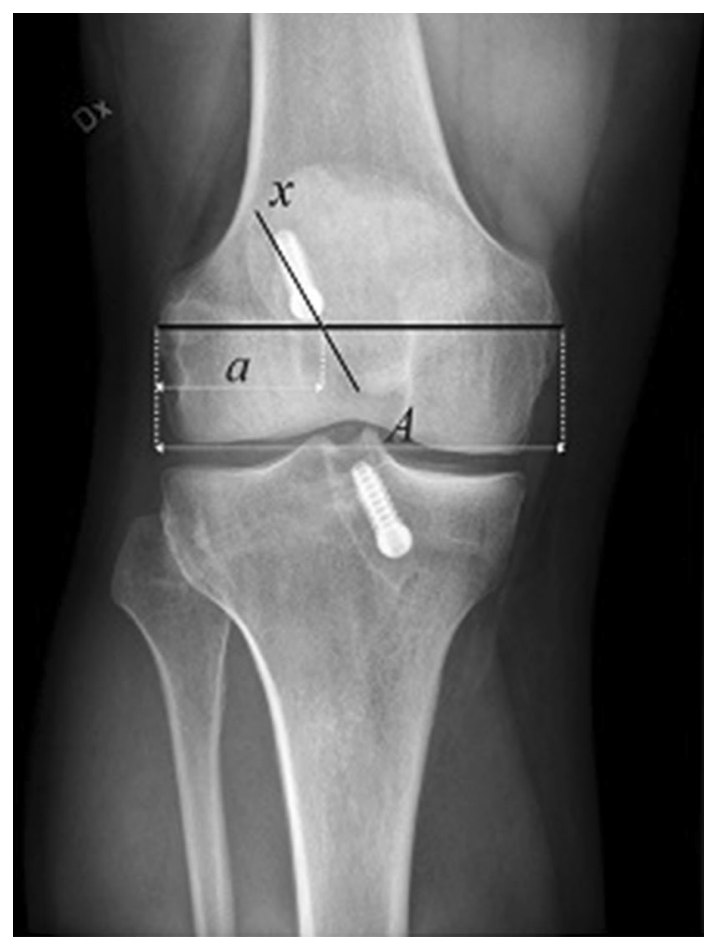

Fig. 1 A radiograph showing the measurement technique for the femoral tunnel position in the coronal plane. The largest distance between the medial and lateral femoral condyles was identified (A). The distance from the lateral condyle to the center of the tunnel was measured (a). The obtained distance (a) was divided by the total width (A) and the position of the femoral tunnel was expressed as a percentage epicondyle was bisected by a line forming the transepicondylar axis (TEA). At the most proximal part of the femur, visualized on the radiograph, a line was drawn along the width of the diaphysis and parallel to the TEA (a). Distal to this line at a distance of half the length of the TEA, another parallel line was drawn (b). The midpoint of lines $a$ and $b$ was crossed by a line parallel to the axis of the diaphysis. The femoral tunnel was visualized and a line was drawn through its axis ( $x$ ) (Fig. 2). The angle formed between this line and line $y$ was defined as the femoral tunnel angle. In a few patients, only a short part of the femur was visible. In these patients, the b-line on occasion was distal to the TEA, in which case the analysis for that particular patient was excluded.

Lateral radiographs were utilized to measure the position of the femoral tunnel in the sagittal plane. When analyzing lateral radiographs, it is important to note and, if necessary, exclude radiographs not obtained from a straight lateral direction. This is ensured by confirming

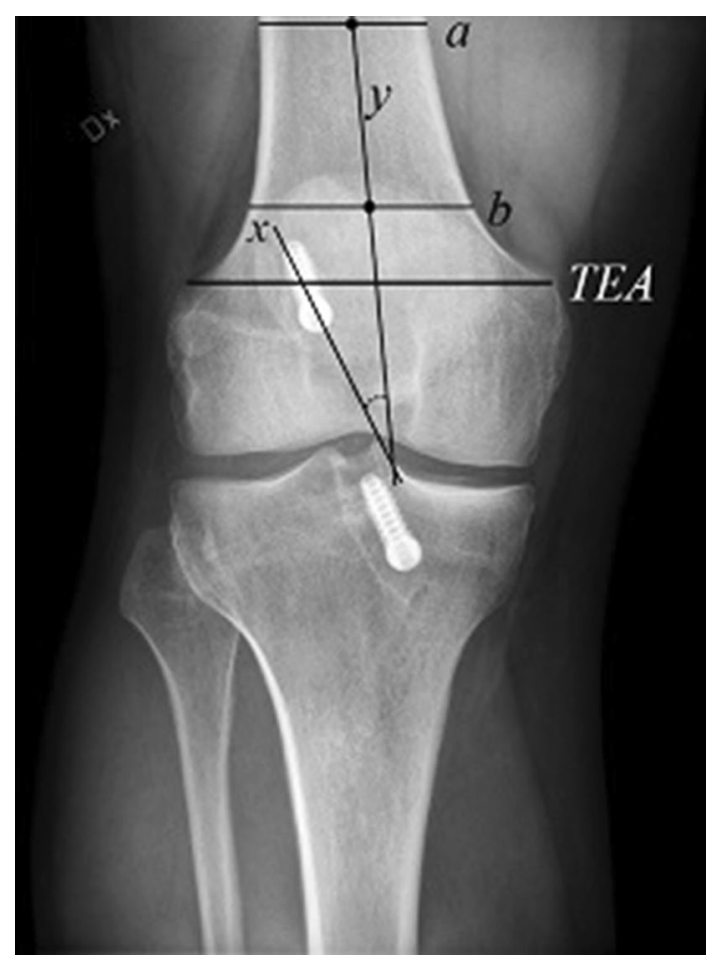

Fig. 2 A radiograph showing the method used to measure the femoral tunnel angle formed by the femoral tunnel and the long axis of the femur in posteroanterior radiographs. The most proximal portion of the femoral epicondyle was bisected by a line forming the transepicondylar axis (TEA). At the most proximal part of the femur, visualized on the radiograph, a line was drawn along the width of the diaphysis and parallel to the TEA (a). Distal to this line, at a distance from line a that corresponds to half the length of the TEA, another parallel line was drawn (b). The midpoint of lines $\mathrm{a}$ and $\mathrm{b}$ was crossed by $\mathrm{a}$ line parallel to the axis of the diaphysis. The femoral tunnel was visualized and a line was drawn through its axis $(x)$. The angle formed between this line and line y was defined as the femoral tunnel angle 
sufficient overlap of the femoral condyles. During the planning of the present study, a method was developed to assess femoral condyle overlap and exclude radiographs not meeting the predetermined criteria (Fig. 3). The first step in the method was to find the center of Blumensaat's line, which was established by measurement. A line was drawn from the posterior to the anterior edge of the femoral condyle (B), intersecting the midpoint at a $45^{\circ}$ angle. The angle size was determined as $45^{\circ}$, since it was estimated to represent the anteroposterior axis of the femoral condyle. Moreover, a line (b) was drawn from the posterior limit of the femoral condyle to the border of the femoral condyle situated just anteriorly (corresponding to the medial or lateral condyle depending on the direction of the rotation of the knee). The femoral condyle overlap was calculated using the formula shown in Fig. 4.

Radiographs were included in the final analysis, assessing the influence on the clinical outcome variables if the overlap of the condyles was larger than $90 \%$, a degree of overlap accepted by Sullivan et al. [30] in a previous study.

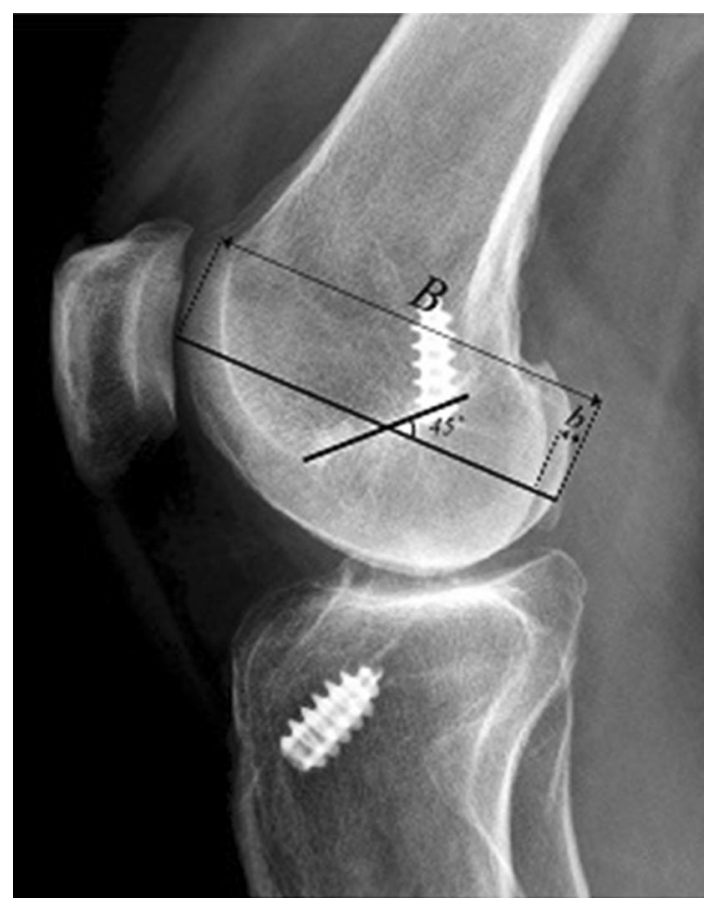

Fig. 3 The radiograph shows the newly developed femoral condyle overlap method, used to validate rotation for lateral radiographs. A line was drawn from the posterior to the anterior edge of the femoral condyle (B), intersecting the midpoint at a $45^{\circ}$ angle. The angle size was determined as $45^{\circ}$, since it was estimated to represent the anteroposterior axis of the femoral condyle. Moreover, a line (b) was drawn from the posterior limit of the femoral condyle to the border of the femoral condyle situated just anteriorly (corresponding to the medial or lateral condyle depending on the direction of the rotation of the knee), whereafter the femoral condyle overlap can be calculated using an equation
Femoral condyle overlap $=100\left(1-\left(\frac{b}{B}\right)\right)$

Fig. 4 Formula used to calculate the femoral condyle overlap

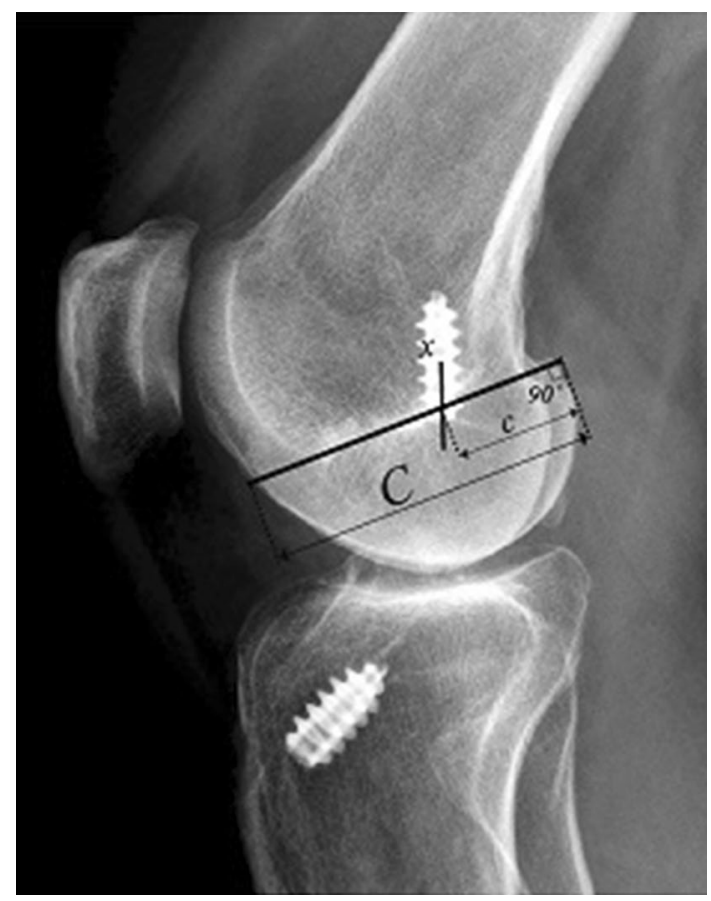

Fig. 5 A radiograph showing the method used to measure the position of the femoral tunnel according to the quadrant method. A grid is placed over the lateral femoral condyle and the superior border is aligned with the Blumensaat line and the inferior border with the distal end of the femoral condyle. The borders of the grid in the anteroposterior directions consist of the most anterior and posterior ends of the femoral condyle, forming distance C. Distance $\mathrm{c}$ is divided by distance $\mathrm{C}$ and the position is presented as a percentage from posterior to anterior (Fig. 4)

An evaluation of the femoral tunnel in the sagittal plane was made using a modified version of the quadrant method [2]. The quadrant method, developed by Bernard and Hertel [2], is widely used in assessments of native and reconstructive ACL anatomy [2, 3, 22, 24]. In the original version, a grid is placed over the lateral femoral condyle, with the superior border aligned with Blumensaat's line and the inferior border with the distal end of the femoral condyle. The borders of the grid in the anteroposterior direction consist of the most anterior and posterior ends of the femoral condyle. However, in the present study, only the anteroposterior position could be evaluated, since there were no radiopaque markers depicting the aperture of the tunnel in the supero-inferior direction. In the present study, the position of the femoral tunnel in the sagittal 
plane, along Blumensaat's line, is presented as a percentage from posterior to anterior (Fig. 5).

\section{Statistical analysis}

Analyses of intrarater and interrater reliability were made using intraclass correlation coefficients (ICC) [28]. Classifications of reliability were made in accordance with Shoukri and Pause [27] as poor $(<0.4)$, good $(0.4-0.75)$ and excellent $(>0.75)$. To analyze dependent variables as a result of the measured radiographic angles and positions, multiple linear regression analysis was used. The dependent variables were assumed to be linearly correlated to the independent variables. Analysis with regard to surgical portal access was performed with Fisher's exact test, the Chi square exact test and the Mann-Whitney $U$ test for dichotomous, ordered categorical and continuous variables, respectively. Value intervals are presented with means and standard deviations, to illustrate differences in outcome depending on graft placement. The selection of the particular intervals was made to divide the patients into three equally sized groups. The continuous and dichotomized outcome variables are presented using statistical beta and odds ratios, respectively. The estimate of the statistical analysis is presented using
Fig. 6 Flow chart of included patients. $A C L$ anterior cruciate ligament, $P A$ posteroanterior, $A P$ anteroposterior

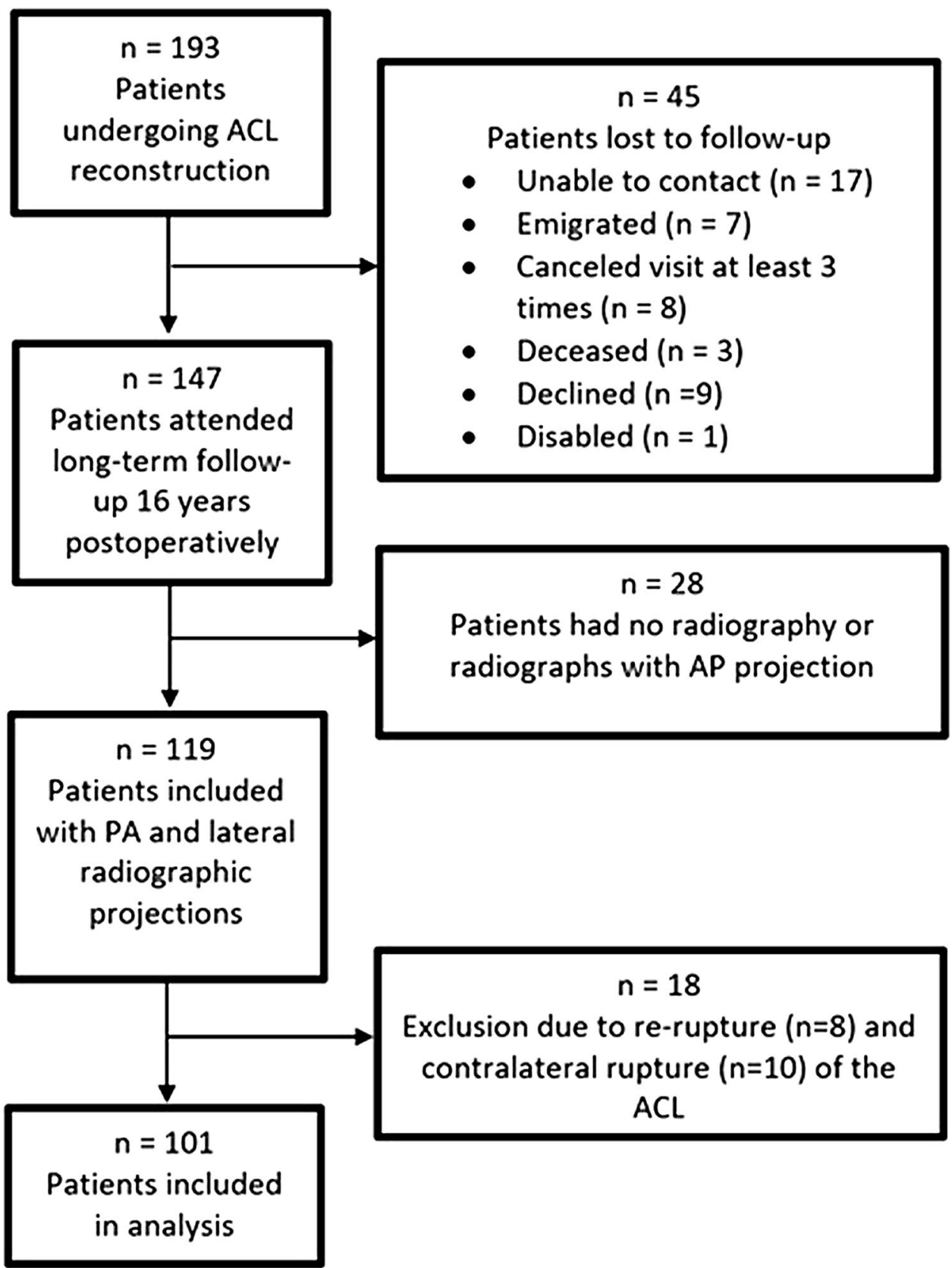


95\% confidence intervals for both continuous and dichotomized variables.

\section{Results}

Of the 193 patients enrolled in the two original randomized, controlled trials, $147(76 \%)$ attended the longterm follow-up at a mean of 16 years postoperatively [4]. Twenty-eight (12\%) patients did not undergo a complete radiographic assessment at follow-up. To standardize the analysis, these patients were excluded. Eight and ten patients sustained a re-rupture and a contralateral rupture of the ACL, respectively. Pre-revision radiographs were available for six of the patients who sustained a rerupture, although these radiographs were not included in the final analysis. Consequently, the radiographs of 101 $(52 \%)$ patients were assessed individually for each parameter needed for inclusion in the study (Fig. 6). Using the femoral condyle overlap method, 18 (9\%) patients had to be excluded from the quadrant method analysis. Moreover, when assessing the femoral tunnel angle, the b-line was found to be distal to the TEA in $10(5 \%)$ patients, leading to their exclusion from analysis. The use of autograft type was similar in the analyzed cohort. The transtibial portal technique was considerably more frequent $(n=72$, $71 \%$ ) compared with the transportal technique $[n=29$, $29 \%$ (Table 1)].

Intra- and interrater reliability were considered excellent for the femoral tunnel angle in the coronal plane (ICC: 0.83 and 0.94), lateral condyle overlap (ICC: 0.97 and 0.90 ) and for the quadrant method (ICC: 0.88 and 0.80 ). When analyzing the reliability of the femoral tunnel position in the coronal plane, the intrarater and interrater reliability were considered good (ICC 0.72 and 0.57 , respectively, Table 2).

Multiple linear regression analysis revealed that neither the angle of the femoral tunnel (Table 3), the position of the femoral tunnel in the coronal plane (Table 4) nor the position of the femoral tunnel in the sagittal plane, assessed using the quadrant method (Table 5), was significantly associated with the assessed outcome variables.

All patients with a bone-patellar tendon-bone autograft were reconstructed using the transtibial technique. Patients with a hamstring tendon autograft underwent reconstruction using either the transtibial (26 patients) or the transportal (29 patients) techniques. Patients undergoing ACL reconstruction using the transtibial technique were examined later (mean $16.9 \pm 0.8$ years) than patients undergoing reconstruction using the transportal technique (mean $15.1 \pm 1.3$ years), $p \leq 0.0001$.

Using the quadrant method, patients reconstructed using a transportal technique had tunnels that were located more posteriorly along Blumensaat's line (mean $38 \pm 5.6 \%$ ) than
Table 1 Demographics of patients at long-term follow-up

\begin{tabular}{ll}
\hline Age at operation, years & $28.7(8.7), n=101$ \\
Gender, male/female & $69 / 32, n=101$ \\
Follow-up period, years & $16.4(1.3), n=101$ \\
Surgical portal technique & \\
Transportal technique & $29(29 \%)$ \\
Transtibial technique & $72(71 \%)$ \\
Type of graft & \\
Bone-patellar tendon-bone autograft & $46(45.5 \%)$ \\
Hamstring tendon autograft & $55(55.5 \%)$ \\
Associated injuries, dichotomized & \\
No & $30(30 \%)$ \\
Yes & $71(70 \%)$ \\
Femoral angle, coronal, degrees & $9.6^{\circ}\left(9.4^{\circ}\right), n=91$ \\
Quadrant method, $\%$ & $40(6.4), n=83$ \\
Femoral tunnel position, coronal, $\%$ & $43(3.5), n=100$ \\
One-leg-hop test, limb symmetry index & $91(19.3), n=92$ \\
IKDC 2000 form ${ }^{\text {a }}$, total score & $71(20.7), n=101$ \\
KT 1000 MMT ${ }^{b}$, mm, side-to-side difference & $1.7(3.0), n=101$ \\
Kellgren-Lawrence, injured side & \\
0 & $29(29 \%)$ \\
1 & $29(29 \%)$ \\
2 & $28(27 \%)$ \\
3 & $10(10 \%)$ \\
Pivot-shift test, dichotomized & $5(5 \%)$ \\
Pivot shift: 0 & $64(64 \%)$ \\
Pivot shift: $1,2,3$ & $36(36 \%)$ \\
Lachman test, dichotomized & $49(48.5 \%)$ \\
Lachman 0 & $52(51.5 \%)$ \\
\hline
\end{tabular}

For categorical variables, $n(\%)$ is presented. For continuous variables, the mean (SD) is presented

${ }^{a}$ International Knee Documentation Committee subjective knee evaluation form

${ }^{\mathrm{b}} \mathrm{KT}-1000$ arthrometer manual maximum test

Table 2 Intraclass correlation coefficients for intrarater and interrater reliability

\begin{tabular}{lll}
\hline Measurement & $\begin{array}{l}\text { Intrarater reli- } \\
\text { ability ICC }(95 \% \\
\text { CI) }\end{array}$ & $\begin{array}{l}\text { Interrater reli- } \\
\text { ability ICC }(95 \% \\
\text { CI })\end{array}$ \\
\hline $\begin{array}{l}\text { Femoral tunnel angle } \\
\begin{array}{l}\text { Femoral tunnel position, } \\
\text { coronal }\end{array}\end{array}$ & $0.83(0.75-0.88)$ & $0.94(0.87-0.97)$ \\
$\begin{array}{l}\text { Femoral condyle overlap } \\
\text { Quadrant method }\end{array}$ & $0.97(0.61-0.80)$ & $0.57(0.26-0.77)$ \\
& $0.88(0.82-0.92)$ & $0.80(0.44-0.92)$
\end{tabular}

ICC Intraclass correlation coefficient, $C I$ Confidence interval 
Table 3 Adjusted multiple linear regression analysis for the femoral tunnel angle

\begin{tabular}{|c|c|c|c|c|c|c|c|}
\hline & & $\begin{array}{l}\text { One-leg-hop test, } \\
\text { mean (SD) }\end{array}$ & $\begin{array}{l}\text { IKDC } 2000 \text {, total } \\
\text { score (SD) }\end{array}$ & $\begin{array}{l}\text { KT-1000 MMT } \\
\text { side-to-side dif- } \\
\text { ference (SD) }\end{array}$ & $\begin{array}{l}\text { Pivot shift } \\
\text { dichotomized ( } 0 \\
\text { vs. } 1+, 2+, 3+) \text {, } \\
n(\%) \text { of events }\end{array}$ & $\begin{array}{l}\text { Lachman test } \\
\text { dichotomized (0 } \\
\text { vs. } 1+, 2+, 3+) \text {, } \\
n(\%) \text { of events }\end{array}$ & $\begin{array}{l}\text { Kellgren-Law- } \\
\text { rence dichoto- } \\
\text { mized ( } 0-1 \text { vs. } \\
2-4), n(\%) \text { of } \\
\text { events }\end{array}$ \\
\hline \multirow{3}{*}{$\begin{array}{l}\text { FTA, value } \\
\text { intervals }\end{array}$} & $-28-<6$ & $88(15.6)$ & $69(19.1)$ & $2.2(3.0)$ & $9(30 \%)$ & $18(58 \%)$ & $15(48 \%)$ \\
\hline & $6-<12.6$ & $94(18.6)$ & 77 (15.9) & $2.2(2.9)$ & $7(23 \%)$ & $14(47 \%)$ & $13(43 \%)$ \\
\hline & $12.6-38.8$ & $93(22.3)$ & $71(24.8)$ & $1.1(3.1)$ & $15(50 \%)$ & $15(50 \%)$ & $11(37 \%)$ \\
\hline $\begin{array}{l}\text { FTA, beta }(95 \% \\
\text { CI) }\end{array}$ & & $\begin{array}{l}-0.23 \\
\quad(-0.71 ; 0.24)\end{array}$ & $\begin{array}{l}-0.35 \\
\quad(-0.81 ; 0.12)\end{array}$ & $\begin{array}{l}-0.04 \\
\quad(-0.11 ; 0.03)\end{array}$ & Not applicable & Not applicable & Not applicable \\
\hline $\begin{array}{l}\text { FTA, OR }(95 \% \\
\text { CI) }\end{array}$ & & Not applicable & Not applicable & Not applicable & $1.05(0.99-1.11)$ & $1.0(0.95-1.05)$ & $1.01(0.96-1.07)$ \\
\hline FTA, $p$-value & & n.s & n.s & n.s & n.s & n.s & n.s \\
\hline Missing patients $^{\mathrm{a}}$ & & 10 & 10 & 10 & 10 & 10 & 10 \\
\hline
\end{tabular}

Multivariate analysis adjusted for the type of graft, surgical portal, associated injuries and age at operation. For the dichotomized variables, the number of events and the percentage of the total number of patients in that particular value interval are presented

$S D$ Standard deviation, IKDC International Knee Documentation Committee, MMT manual maximum test, FTA femoral tunnel angle, $C I$ confidence interval, $O R$ odds ratio, $N$ s not significant

${ }^{a}$ Missing patients are patients with incomplete data for the particular analysis, details regarding this can be found in the results section

Table 4 Adjusted linear regression analysis for the femoral tunnel position in the coronal plane

\begin{tabular}{|c|c|c|c|c|c|c|c|}
\hline & & $\begin{array}{l}\text { One-leg-hop } \\
\text { test, mean (SD) }\end{array}$ & $\begin{array}{l}\text { IKDC 2000, } \\
\text { total score (SD) }\end{array}$ & $\begin{array}{l}\text { KT-1000 MMT } \\
\text { side-to-side dif- } \\
\text { ference (SD) }\end{array}$ & $\begin{array}{l}\text { Pivot shift } \\
\text { dichotomized }(0 \\
\text { vs. } 1+, 2+, 3+) \text {, } \\
n(\%) \text { of events }\end{array}$ & $\begin{array}{l}\text { Lachman test } \\
\text { dichotomized }(0 \\
\text { vs. } 1+, 2+, 3+) \text {, } \\
n(\%) \text { of events }\end{array}$ & $\begin{array}{l}\text { Kellgren-Law- } \\
\text { rence dichoto- } \\
\text { mized }(0-1 \text { vs. } \\
2-4), n(\%) \text { of } \\
\text { events }\end{array}$ \\
\hline \multirow{3}{*}{$\begin{array}{l}\text { FTP coronal, } \\
\text { value intervals }\end{array}$} & $31.2-<41.5$ & $95(26.5)$ & $72(20.3)$ & $1.9(2.8)$ & $9(27 \%)$ & $16(49 \%)$ & $11(33 \%)$ \\
\hline & $41.5<44.9$ & $93(15.0)$ & $74(19.1)$ & $1.9(2.6)$ & $15(46 \%)$ & $18(53 \%)$ & $15(44 \%)$ \\
\hline & $44.9-48.9$ & $87(14.4)$ & $69(23.1)$ & $1.5(3.5)$ & $11(33 \%)$ & $18(55 \%)$ & $17(52 \%)$ \\
\hline $\begin{array}{l}\text { FTP coronal, } \\
\text { beta }(95 \% \mathrm{CI})\end{array}$ & & $\begin{array}{l}-0.88 \\
\quad(-2.10 ; 0.34)\end{array}$ & $\begin{array}{l}0.70 \\
\quad(-0.43 ; 1.84)\end{array}$ & $\begin{array}{l}-0.01 \\
\quad(-0.18 ; 0.17)\end{array}$ & Not applicable & Not applicable & Not applicable \\
\hline $\begin{array}{l}\text { FTP coronal, OR } \\
(95 \% \mathrm{CI})\end{array}$ & & Not applicable & Not applicable & Not applicable & $1.04(0.92-1.18)$ & $1.01(0.90-1.14)$ & $0.95(0.83-1.08)$ \\
\hline $\begin{array}{l}\text { FTP coronal, } \\
p \text {-value }\end{array}$ & & N.s & N.s & N.s & N.s & N.s & N.s \\
\hline Missing patients $^{\mathrm{a}}$ & & 1 & 1 & 1 & 1 & 1 & 1 \\
\hline
\end{tabular}

Multivariate analysis adjusted for the type of graft, surgical portal, associated injuries and age at operation. For the dichotomized variables, the number of events and the percentage of the total number of patients in that particular value interval are presented

$S D$ Standard deviation, IKDC International Knee Documentation Committee, MMT manual maximum test, FTA femoral tunnel angle, $C I$ confidence interval, $O R$ odds ratio, $N$ s not significant

${ }^{a}$ Missing patients are patients with incomplete data for the particular analysis, details regarding this can be found in the results section

patients in whom the transtibial technique was utilized (mean $41 \pm 6.5 \%$ ). However, the result was not statistically significant. Similarly, the surgical portal that was used had no significant influence on the femoral tunnel angle (TP: 11. $0^{\circ} \pm 8.6$, TT: $8.9^{\circ} \pm 9.7$, Table 6) .

\section{Discussion}

The most important finding was that the placement and angle of the femoral tunnel after non-anatomic ACL reconstruction did not predict the clinical, subjective or radiographic outcome at a mean of 16 years postoperatively, but the measurement methods were found to be reliable. Contrary to our results, Pinczewski et al. [26] performed a study of 200 patients who underwent clinical and radiologic 
Table 5 Adjusted linear regression analysis for the quadrant method

$\begin{array}{ll}\text { One-leg-hop } & \text { IKDC 2000, } \\ \text { test, mean (SD) } & \text { total score (SD) }\end{array}$

KT-1000 MMT
side-to-side dif-
ference (SD)

Pivot shift

Lachman test

Kellgren-Lawdichotomized $(0 \quad$ dichotomized $(0$ vs. $1+, 2+, 3+), \quad$ vs. $1+, 2+, 3+)$, ence dichoto( $n(\%)$ of events $\quad n(\%)$ of events $\quad 2-4), n(\%)$ of events

\begin{tabular}{|c|c|c|c|c|c|c|c|}
\hline \multirow{3}{*}{$\begin{array}{l}\text { Quadrant } \\
\text { method, value } \\
\text { intervals }\end{array}$} & $27.3-<37.5$ & 93 (18.7) & $78(14.0)$ & $2.0(2.7)$ & $11(39 \%)$ & $14(52 \%)$ & $8(30 \%)$ \\
\hline & $37.5-<42.9$ & $91(13.2)$ & $67(23.4)$ & $1.6(3.3)$ & $11(41 \%)$ & $12(43 \%)$ & $11(39 \%)$ \\
\hline & $42.9-57.8$ & $97(22.8)$ & $74(20.0)$ & $1.5(3.1)$ & $10(37 \%)$ & $17(61 \%)$ & $13(46 \%)$ \\
\hline $\begin{array}{l}\text { Quadrant } \\
\text { method, beta } \\
(95 \% \mathrm{CI})\end{array}$ & & $\begin{array}{l}0.41 \\
\quad(-0.28 ; 1.11)\end{array}$ & $\begin{array}{l}-0.03 \\
\quad(-0.69 ; 0.63)\end{array}$ & $\begin{array}{l}0.01 \\
\quad(-0.10 ; 0.12)\end{array}$ & & & \\
\hline $\begin{array}{l}\text { Quadrant } \\
\text { method, OR } \\
(95 \% \mathrm{CI})\end{array}$ & & & & & $0.95(0.88-1.03)$ & $1.00(0.93-1.08)$ & $1.04(0.96-1.12)$ \\
\hline $\begin{array}{c}\text { Quadrant } \\
\text { method, } \\
p \text {-value }\end{array}$ & & n.s & n.s & n.s & n.s & n.s & n.s \\
\hline Missing patients ${ }^{\mathrm{a}}$ & & 18 & 18 & 18 & 18 & 18 & 18 \\
\hline
\end{tabular}

Multivariate analysis adjusted for the type of graft, surgical portal, associated injuries and age at operation. For the dichotomized variables, the number of events and the percentage of the total number of patients in that particular value interval are presented

$S D$ Standard deviation, IKDC International Knee Documentation Committee, MMT manual maximum test, FTA femoral tunnel angle, CI confidence interval, $O R$ odds ratio, $N s$ not significant

${ }^{\mathrm{a}}$ Missing patients are patients with incomplete data for the particular analysis, details regarding this can be found in the results section

Table 6 Comparisons by surgical portal

\begin{tabular}{|c|c|c|c|}
\hline & $\begin{array}{l}\text { Transportal technique } \\
(n=29)\end{array}$ & $\begin{array}{l}\text { Transtibial technique } \\
(n=72)\end{array}$ & $p$ value \\
\hline \multicolumn{4}{|l|}{ Type of graft } \\
\hline Bone-patellar tendon-bone autograft & $0(0 \%)$ & $46(64 \%)$ & \multirow[t]{2}{*}{$<0.0001$} \\
\hline Hamstring tendon autograft & $29(100 \%)$ & $26(36 \%)$ & \\
\hline Age at operation, years & $26.3(6.2)$ & $29.7(9.4)$ & $\mathrm{n} . \mathrm{s}$ \\
\hline Follow-up period, years & $15.1(1.3)$ & $16.9(0.8)$ & $<0.0001$ \\
\hline \multicolumn{4}{|l|}{ Associated injuries, dichotomized } \\
\hline No & $8(28 \%)$ & $22(31 \%)$ & \multirow[t]{2}{*}{ n.s } \\
\hline Yes & $21(72 \%)$ & $50(69 \%)$ & \\
\hline Femoral angle, coronal, degrees & $11.0(8.6)$ & $8.9(9.7)$ & n.s \\
\hline Quadrant method, \% & $38(5.6)$ & $41(6.5)$ & n.s \\
\hline Femoral tunnel position, coronal, $\%$ & $43(3.5)$ & $43(3.6)$ & n.s \\
\hline \multicolumn{4}{|l|}{ Kellgren-Lawrence, injured side } \\
\hline 0 & $8(28 \%)$ & $21(29 \%)$ & \multirow[t]{5}{*}{ n.s } \\
\hline 1 & $9(31 \%)$ & $20(28 \%)$ & \\
\hline 2 & $9(31 \%)$ & $19(26 \%)$ & \\
\hline 3 & $3(10 \%)$ & $7(10 \%)$ & \\
\hline 4 & $0(0 \%)$ & $5(7 \%)$ & \\
\hline \multicolumn{4}{|l|}{ Pivot-shift test, dichotomized } \\
\hline Pivot shift: 0 & $22(76 \%)$ & $42(69 \%)$ & \multirow[t]{2}{*}{ n.s } \\
\hline Pivot shift: $1,2,3$ & $7(24 \%)$ & $29(31 \%)$ & \\
\hline \multicolumn{4}{|l|}{ Lachman test, dichotomized } \\
\hline Lachman 0 & $15(52 \%)$ & $34(47 \%)$ & \multirow[t]{2}{*}{ n.s } \\
\hline Lachman $1,2,3$ & $14(48 \%)$ & $38(53 \%)$ & \\
\hline
\end{tabular}

Analysis with regard to surgical portal technique. For categorical variables, $n(\%)$ is presented. For continuous variables, the mean $(\mathrm{SD})$ is presented

Ns not significant 
assessment 7 years after ACL reconstruction. The authors reported that a more vertical graft in the coronal plane was significantly correlated to inferior rotational stability and an increased level of OA. A similar but non-identical measurement methodology was used in their study, which could partly explain the differences. Moreover, Pinczewski et al. [26] only included patients with hamstring tendon grafts. One important difference is that the mean follow-up period in the present study was 16 years compared with 7 years in the study by Pinczewski et al. [26]. It is well known that ACL injury is associated with an increased risk of developing OA [21]. In time, differences in function and stability could possibly level out, as a result of the general joint degeneration.

The present study found no significant differences in outcome when patient groups were compared based on the surgical portal technique. However, patients who underwent transtibial ACL reconstruction had tunnel apertures that were more anteriorly placed along the Blumensaat line compared with those who underwent the transportal technique. This was probably a result of the restriction caused by the angle of the tibial tunnel when the drilling of the femoral tunnel was performed. A recent systematic review established that the mean position of the native femoral insertion was $28.4 \% \pm 5.1 \%$ from the posterior border when using the quadrant method [34]. Consequently, in the present study, the transportal technique displayed a tendency towards producing femoral tunnels closer to the native ACL anatomy. Previous studies have also shown that the femoral tunnel angle is more horizontal in patients reconstructed using transportal techniques [5, 14]. In the present study, the femoral tunnel angle was not affected by the choice of surgical portal. The probable reason for this is that the patients were reconstructed prior to the implementation of the transportal anatomic ACL reconstruction and the surgeons strove to achieve optimal isometry not anatomy. The opportunity to utilize the increased maneuverability inherent to the transportal approach was therefore not taken.

The femoral tunnel angle and the position of the femoral tunnel in the frontal and the sagittal plane were assumed to be linearly correlated to the outcome variables. This assumption was based on studies that have determined the native anatomic positions of the ACL insertion to the femur. Measurements in the current study showed that no femoral tunnel angle was larger than what was regarded as "within anatomic range" by the originators of the utilized method [14]. Similarly, no tunnel was closer to the posterior border of the quadrant than the synthesized position presented in a recent systematic review assessing the native femoral insertion of the ACL [34]. Since anatomic ACL reconstruction is considered superior in terms of mitigating rotational laxity in the short- to mid-term perspective, the authors of the present study consider it natural to assume a linear correlation towards more anatomic positioning [13]. However, it is important to recognize that the patients in the present study, in spite of having femoral tunnels within the limits of what the reference literature considers to be within the anatomic range, were not necessarily anatomically reconstructed. Since all measurements were made in only one projection, such conclusions cannot be drawn. Moreover, to determine anatomic graft placement, both tibial and femoral tunnel positioning must be assessed.

The inter- and intrarater reliability, analyzed using intraclass correlation coefficients, of the performed measurements were considered excellent or good. These results are in line with previous studies showing that measurements of the femoral tunnel angle, [14] the quadrant method [18, 30] and the coronal femoral tunnel position [26] are reliable. Moreover, the good validity of the Bernard quadrant method has previously been established in a study comparing 3D-CT images with standard radiographs [18].

In the present study, the femoral condyle overlap method was shown to be highly reliable. Although not yet validated against other quantitative measurement methods, a similar strategy using $90 \%$ condyle-to-condyle overlap has previously been used [30]. Further, since the femoral condyle overlap method is used to specify which radiographs can be used to assess the position of the femoral tunnel in the sagittal plane, potential varus or valgus deviation would not affect the interpretation of the outcome. It, therefore, appears to be superior to evaluate knee rotation by measuring the anteroposterior axis of the femoral condyle and not the total area of the femoral condyle overlap. It is evident that the availability of an objective method to determine the rotation of lateral radiographs is useful. The method is able to determine which radiographs are of sufficient quality for research purposes. Using the fluoroscopic technique to obtain optimal lateral radiographs is superior, but, using the femoral condyle overlap analysis method, data from previous studies can be analyzed without needing to re-examine patients using fluoroscopy.

There are some limitations that need to be mentioned. First, of 193 patients, 147 (76\%) attended the clinical assessment after a mean of 16 years. Regrettably, several patients had no radiographs or had incorrect projections to enable a standardized analysis. Additional patients were excluded due to re-rupture or contralateral ACL rupture. Patients with a re-rupture were excluded, since the performance of the original tunnel of the primary ACL reconstruction could no longer be assessed. Too few pre-revision radiographs were available to perform a statistically adequate separate analysis of predictors of re-rupture. Patients with a contralateral ACL injury were excluded, since the comparison between the index and the contralateral knee would be confounded. Importantly, a few possible confounders, such as age, graft type, associated injuries and the surgical portal technique, 
could be adjusted in order to use the logistic regression analysis. However, a possible confounder we were not able to adjust for was the use of multiple surgeons. Further, since this was a retrospective study, an à priori power analysis could not be performed. Moreover, the femoral tunnel is only one of the variables in a biomechanical system. There are other variables, such as the tibial tunnel and the properties of the graft, which affect the function of the reconstructed knee. The most important limitation is, of course, that the anatomic reconstruction principles were not known or adhered to at the time the study was conducted.

\section{Conclusion}

The orientation of the femoral tunnel did not predict the long-term subjective outcome, functional outcome or the development of osteoarthritis in patients undergoing nonanatomic ACL reconstruction. The method for determining femoral rotation on lateral radiographs was found to be reliable.

Funding This research did not receive any specific grants.

\section{Compliance with ethical standards}

Conflict of interest The authors have no relevant conflicts of interest to declare.

Ethical approval The study was approved by the Human Ethics Committee at Gothenburg University and Stockholm University.

Informed consent Written informed consent was obtained from all patients.

OpenAccess This article is distributed under the terms of the Creative Commons Attribution 4.0 International License (http://creativeco mmons.org/licenses/by/4.0/), which permits unrestricted use, distribution, and reproduction in any medium, provided you give appropriate credit to the original author(s) and the source, provide a link to the Creative Commons license, and indicate if changes were made.

\section{References}

1. Araujo PH, Kfuri Junior M, Ohashi B, Hoshino Y, Zaffagnini S, Samuelsson K et al (2014) Individualized ACL reconstruction. Knee Surg Sports Traumatol Arthrosc 22:1966-1975

2. Bernard M, Hertel P, Hornung H, Cierpinski T (1997) Femoral insertion of the ACL. Radiographic quadrant method. Am J Knee Surg 10:14-21. (discussion 21-12)

3. Bird JH, Carmont MR, Dhillon M, Smith N, Brown C, Thompson $\mathrm{P}$ et al (2011) Validation of a new technique to determine midbundle femoral tunnel position in anterior cruciate ligament reconstruction using 3-dimensional computed tomography analysis. Arthroscopy 27:1259-1267
4. Bjornsson H, Samuelsson K, Sundemo D, Desai N, Sernert N, Rostgard-Christensen L et al (2016) A randomized controlled trial with mean 16-year follow-up comparing hamstring and patellar tendon autografts in anterior cruciate ligament reconstruction. Am J Sports Med 44:2304-2313

5. Celiktas M, Kose O, Sarpel Y, Gulsen M (2015) Can we use intraoperative femoral tunnel length measurement as a clue for proper femoral tunnel placement on coronal plane during ACL reconstruction? Arch Orthop Trauma Surg 135:523-528

6. Daniel DM, Malcom LL, Losse G, Stone ML, Sachs R, Burks $R$ (1985) Instrumented measurement of anterior laxity of the knee. J Bone Jt Surg Am 67:720-726

7. Ejerhed L, Kartus J, Sernert N, Köhler K, Karlsson J (2003) Patellar tendon or semitendinosus tendon autografts for anterior cruciate ligament reconstruction? A prospective randomized study with a two-year follow-up. Am J Sports Med 31(1):19-25

8. Galway HR, MacIntosh DL (1980) The lateral pivot shift: a symptom and sign of anterior cruciate ligament insufficiency. Clin Orthop Relat Res 147:45-50

9. Getgood A, Spalding T (2012) The evolution of anatomic anterior cruciate ligament reconstruction. Open Orthop J 6:287-294

10. Hoshino Y, Araujo P, Ahlden M, Moore CG, Kuroda R, Zaffagnini $S$ et al (2012) Standardized pivot shift test improves measurement accuracy. Knee Surg Sports Traumatol Arthrosc 20:732-736

11. Howell SM, Gittins ME, Gottlieb JE, Traina SM, Zoellner TM (2001) The relationship between the angle of the tibial tunnel in the coronal plane and loss of flexion and anterior laxity after anterior cruciate ligament reconstruction. Am J Sports Med 29:567-574

12. Howell SM, Wallace MP, Hull ML, Deutsch ML (1999) Evaluation of the single-incision arthroscopic technique for anterior cruciate ligament replacement. A study of tibial tunnel placement, intraoperative graft tension, and stability. Am J Sports Med 27:284-293

13. Hussein M, van Eck CF, Cretnik A, Dinevski D, Fu FH (2012) Prospective randomized clinical evaluation of conventional single-bundle, anatomic single-bundle, and anatomic double-bundle anterior cruciate ligament reconstruction: 281 cases with $3-$ to 5-year follow-up. Am J Sports Med 40:512-520

14. Illingworth KD, Hensler D, Working ZM, Macalena JA, Tashman S, Fu FH (2011) A simple evaluation of anterior cruciate ligament femoral tunnel position: the inclination angle and femoral tunnel angle. Am J Sports Med 39:2611-2618

15. Irrgang JJ, Anderson AF, Boland AL, Harner CD, Kurosaka M, Neyret $P$ et al (2001) Development and validation of the international knee documentation committee subjective knee form. Am J Sports Med 29:600-613

16. Jepsen CF, Lundberg-Jensen AK, Faunoe P (2007) Does the position of the femoral tunnel affect the laxity or clinical outcome of the anterior cruciate ligament-reconstructed knee? A clinical, prospective, randomized, double-blind study. Arthroscopy 23:1326-1333

17. Kellgren JH, Lawrence JS (1957) Radiological assessment of osteo-arthrosis. Ann Rheum Dis 16:494-502

18. Kim DH, Lim WB, Cho SW, Lim CW, Jo S (2016) Reliability of 3-dimensional computed tomography for application of the bernard quadrant method in femoral tunnel position evaluation after anatomic anterior cruciate ligament reconstruction. Arthroscopy 32:1660-1666

19. Laxdal G, Kartus J, Hansson L, Heidvall M, Ejerhed L, Karlsson $\mathrm{J}$ (2005) A prospective randomized comparison of bone-patellar tendon-bone and hamstring grafts for anterior cruciate ligament reconstruction. Arthroscopy 21(1):34-42

20. Lee MC, Seong SC, Lee S, Chang CB, Park YK, Jo H et al (2007) Vertical femoral tunnel placement results in rotational knee 
laxity after anterior cruciate ligament reconstruction. Arthroscopy 23:771-778

21. Lohmander LS, Englund PM, Dahl LL, Roos EM (2007) The long-term consequence of anterior cruciate ligament and meniscus injuries: osteoarthritis. Am J Sports Med 35:1756-1769

22. Lorenz S, Elser F, Mitterer M, Obst T, Imhoff AB (2009) Radiologic evaluation of the insertion sites of the 2 functional bundles of the anterior cruciate ligament using 3-dimensional computed tomography. Am J Sports Med 37:2368-2376

23. Morgan JA, Dahm D, Levy B, Stuart MJ (2012) Femoral tunnel malposition in ACL revision reconstruction. J Knee Surg 25:361-368

24. Musahl V, Burkart A, Debski RE, Van Scyoc A, Fu FH, Woo SL (2003) Anterior cruciate ligament tunnel placement: Comparison of insertion site anatomy with the guidelines of a computerassisted surgical system. Arthroscopy 19:154-160

25. Nakagawa T, Hiraoka H, Fukuda A, Kuribayashi S, Nakayama S, Matsubara T et al (2007) Fluoroscopic-based navigation-assisted placement of the tibial tunnel in revision anterior cruciate ligament reconstruction. Arthroscopy 23:443.e441-443.e444

26. Pinczewski LA, Salmon LJ, Jackson WF, von Bormann RB, Haslam PG, Tashiro S (2008) Radiological landmarks for placement of the tunnels in single-bundle reconstruction of the anterior cruciate ligament. J Bone Jt Surg Br 90:172-179

27. Shoukri MM, Cihon C (1998) Statistical methods for health sciences. CRC Press, Boca Raton

28. Shrout PE, Fleiss JL (1979) Intraclass correlations: uses in assessing rater reliability. Psychol Bull 86:420-428
29. Sommer C, Friederich NF, Muller W (2000) Improperly placed anterior cruciate ligament grafts: correlation between radiological parameters and clinical results. Knee Surg Sports Traumatol Arthrosc 8:207-213

30. Sullivan JP, Matava MJ, Flanigan DC, Gao Y, Britton CL, Amendola A et al (2012) Reliability of tunnel measurements and the quadrant method using fluoroscopic radiographs after anterior cruciate ligament reconstruction. Am J Sports Med 40:2236-2241

31. Tegner Y, Lysholm J, Lysholm M, Gillquist J (1986) A performance test to monitor rehabilitation and evaluate anterior cruciate ligament injuries. Am J Sports Med 14:156-159

32. Topliss C, Webb J (2001) An audit of tunnel position in anterior cruciate ligament reconstruction. Knee 8:59-63

33. Trojani C, Sbihi A, Djian P, Potel JF, Hulet C, Jouve F et al (2011) Causes for failure of ACL reconstruction and influence of meniscectomies after revision. Knee Surg Sports Traumatol Arthrosc 19:196-201

34. Xu H, Zhang C, Zhang Q, Du T, Ding M, Wang Y et al (2016) A systematic review of anterior cruciate ligament femoral footprint location evaluated by quadrant method for single-bundle and double-bundle anatomic reconstruction. Arthroscopy 32:1724-1734

Publisher's Note Springer Nature remains neutral with regard to jurisdictional claims in published maps and institutional affiliations. 